\title{
DETERMINATION OF THERMAL DECOMPOSITION REACTION CHARACTERISTICS $(A, E)$ OF WOOD SAMPLES FOR FIRE DYNAMICS SIMULATION
}

\author{
László Beda ${ }^{1}$ and Attila Szabó ${ }^{2}$ \\ ${ }^{1}$ Institute of Disaster Management and Fire Protection Engineering, Szent István University \\ beda.laszlo@ybl.szie.hu \\ ${ }^{2}$ NDGDM Disaster Management Research Institute \\ kok.tvl@katved.gov.hu
}

\begin{abstract}
The purpose of this work is to determine the pre-exponential factor (A) and the reaction activation energy (E) of decomposition reactions that are needed for Fire Dynamics Simulation (FDS) using Derivatograph $Q 1500 D$.

The materials we investigated: Pine Wood Board (PWB), Multilayered Parquet Board (MPB), Particleboard Core (PBC) and Oriented Standard Board (OSB).
\end{abstract}

Keywords: fire simulation, FDS, wood pyrolysis, activation energy, pre-exponential factor

\section{INTRODUCTION}

Recently the dynamics of a fire can be studied numerically providing sufficient data are available for the simulations. The fact is that the data needed to characterize the degradation of the condensed phase materials that supply the fuel may not be available. Therefore, the current demands for the Fire Dynamics Simulator (FDS), which is a powerful tool to estimate the process of fire, require reliable input data to calculate the pyrolysis rate of the burning solid material. In our work we investigate wood and wood products that are thermally degradable and combustible materials and can contribute to the harmful results of unwanted fires. FDS can be used to model different phenomena of the fire (e.g.: radiative and convective heat transfer between the solid and gas surfaces, flame spread and fire growth etc.) including the pyrolysis. It is assumed that the pyrolysis of the solid material takes place at the surface, thus the heat required to vaporize fuel is extracted from the incoming energy flux. 
The distinction between fuel pyrolysis and oxidation should be done because their heat of reaction is extremely different, and this heat of reaction could control the process. In cellulose experiments in air at $190^{\circ} \mathrm{C}$ the oxidative degradation is predominant, but above $300^{\circ} \mathrm{C}$ pyrolysis is dominant.

The difference in activation energy should reflect this behaviour; the activation energy of cellulose pyrolysis is higher than the one of cellulose oxidation [1].

The pyrolysis rate is given by an Arrhenius type expression [2]:

$$
\dot{m}^{\prime \prime}=A \rho_{s} e^{-E_{A} / R T}
$$

Where

$$
\begin{array}{ll}
\dot{m}^{\prime \prime} & - \text { is the mass loss rate, } \\
A & - \text { is the pre-exponential factor, } \\
\rho_{s} & - \text { is the density, } \\
E_{A} & - \text { is the activation energy, } \\
R & - \text { is the universal gas constant }(8.314 \mathrm{~J} / \mathrm{molK}) \\
T & - \text { is the temperature. }
\end{array}
$$

Equation 1 shows that first order reaction kinetics is assumed in the model, so in the followings we considered the decomposition reactions to take place according to this assumption.

\section{METHODS AND MATERIALS}

In our work, we used Derivatograph $Q 1500 D$ which is an instrument for simultaneous TG, DTG, DTA and TA investigations, using non-isothermal, isothermal and quasi-isothermal heating techniques [3]. The samples were heated in Derivatograph $Q 1500 D$ in static air atmosphere at a temperature range of $20-500^{\circ} \mathrm{C}$ with linear heating rate of $10^{\circ} \mathrm{C} \mathrm{min}^{-1}$. The weight loss (TG), the differential thermo-analytical curve (DTA) and the temperature changes (T) were recorded as a function of time. From the results the rate of conversion $(\alpha)$ was calculated and the rate of conversion were plotted as a function of temperature. 


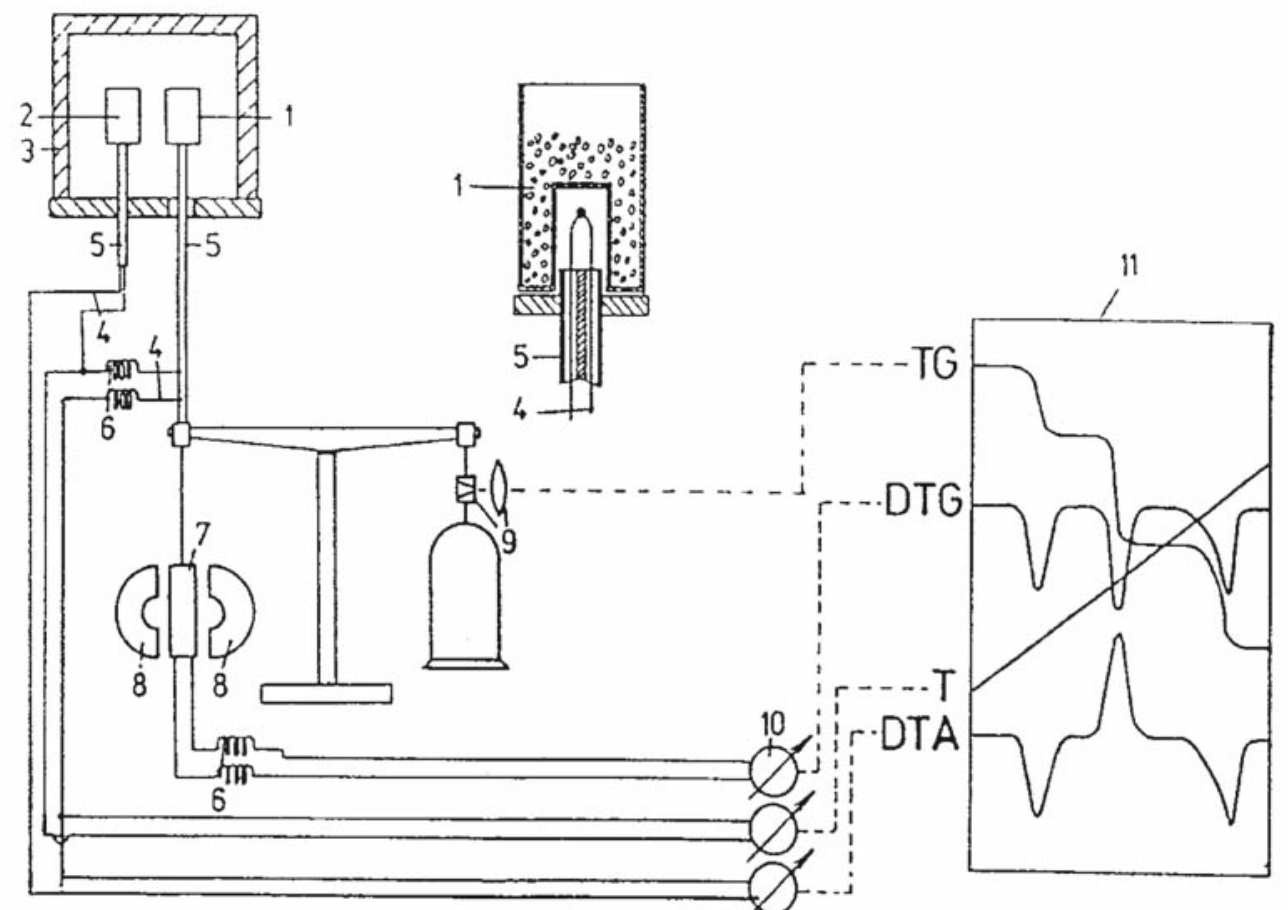

1-sample, 2-reference material, 3-furnace, 4-thermocouples, 5-corundum tubes, 6-flexible junction, 7-coil, 8-magnet, 9-optical system, 10-galvanometers, 11-recorded data

Figure 1. Scheme of Derivatograph Q 1500D

Three parallel samples were tested; the characteristic sample parameters were as follows (Fig. 2):

Pine Wood Board (PWB): sample size - $120.0 \mathrm{mg}$, residue - $30.4 \mathrm{mg}$

Multilayered Parquet Board (MPB): sample size - $120.0 \mathrm{mg}$, residue $-27.9 \mathrm{mg}$

Particleboard Core (PBC), - $120.1 \mathrm{mg}$, residue $-31.1 \mathrm{mg}$

Oriented Standard Board $(O S B)-120.2 \mathrm{mg}$, residue $-26.9 \mathrm{mg}$

The composition of MPB, PBC, and OSB: approximately 90-95\% wood, 10-5\% carbamidephenol-formaldehyde resin.

Prior to the experiments the samples were stored in room temperature $\left(25^{\circ} \mathrm{C}, 50 \%\right.$ relative humidity) for two weeks.
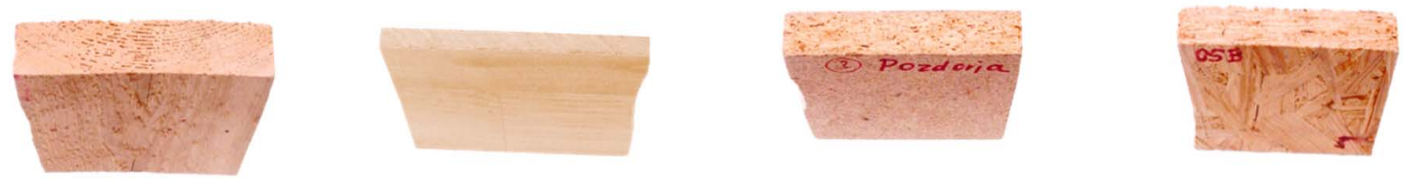

Figure 2. Photos of samples from left to right: PWB, MPB, PBC, OSB 


\section{RESULTS AND DISCUSSIONS}

As wood reaches elevated temperature, the different chemical components undergo thermal degradation. Thermal degradation can be broken up into four temperature regimes that are distinguished in the literature [4].

- Between $100^{\circ} \mathrm{C}$ and $200^{\circ} \mathrm{C}$, wood becomes dehydrated and generates water vapour and other non-combustible gases and liquids including $\mathrm{CO}_{2}$, formic acid, acetic acid, and $\mathrm{H}_{2} \mathrm{O}$.

- From $200{ }^{\circ} \mathrm{C}$ to $300{ }^{\circ} \mathrm{C}$, some wood components begin to undergo significant pyrolysis, the hemicelluloses and lignin components are pyrolyzed in this range. Dehydration reactions around $200{ }^{\circ} \mathrm{C}$ are primarily responsible for pyrolysis of hemi cellulose and lignin and results in a high char yield for wood. Although cellulose remains mostly unpyrolyzed, its thermal degradation can be accelerated in the presence of water, acids, and oxygen. Overall pyrolysis reactions are endothermic due to decreasing dehydration and increasing $\mathrm{CO}$ formation from porous char reactions with $\mathrm{H}_{2} \mathrm{O}$ and $\mathrm{CO}_{2}$.

- The third temperature regime is from $300{ }^{\circ} \mathrm{C}$ to $450{ }^{\circ} \mathrm{C}$ and begins with significant depolymerisation of cellulose in the range $300-350^{\circ} \mathrm{C}$. Finally, the carbon-carbon linkage between lignin structural units is cleaved from $370{ }^{\circ} \mathrm{C}$ to $400{ }^{\circ} \mathrm{C}$. The degradation reaction of lignin is an exothermic reaction, occurring between $225^{\circ} \mathrm{C}$ and $450{ }^{\circ} \mathrm{C}$.

- At $>450{ }^{\circ} \mathrm{C}$, the remaining wood residue is char, which undergoes further degradation by being oxidized to $\mathrm{CO}_{2}, \mathrm{CO}$, and $\mathrm{H}_{2} \mathrm{O}$. This is referred to as afterglow.

In composites, decomposition of the pure wood can be modified by the resin content but we did not analyze this effect as our aim was to gain gross kinetic parameters for fire modelling.

Derivatograms and conversion-temperature curves are represented in Figures 3-10 for each material.

The TG curves (Fig. 3,5,7,10) indicate the temperature regimes of decomposition.

The results are summarized in Table 1.

\begin{tabular}{|l|r|r|r|r|}
\hline \multirow{2}{*}{ Decomposition stages } & \multicolumn{4}{|c|}{ Sample } \\
\cline { 2 - 5 } & \multicolumn{1}{|c|}{ PWB } & \multicolumn{1}{c|}{ MPB } & \multicolumn{1}{c|}{ PBC } & \multicolumn{1}{c|}{ OSB } \\
\hline Elimination of moisture $\left({ }^{\circ} \mathrm{C}\right)$ & $80-130$ & $80-130$ & $70-120$ & $70-150$ \\
\hline Active decomposition $\left({ }^{\circ} \mathrm{C}\right)$ & $140-220$ & $140-220$ & $160-230$ & $160-210$ \\
\hline Pyrolysis $\left({ }^{\circ} \mathrm{C}\right)$ & $230-360$ & $230-350$ & $220-360$ & $215-360$ \\
\hline
\end{tabular}

Table 1. Decomposition temperatures 
The curves of all samples show slight differences in the characteristic temperatures shown in Table 1. Pyrolysis takes place between 220 and $360^{\circ} \mathrm{C}$.

The kinetic parameters were determined for this temperature regime.

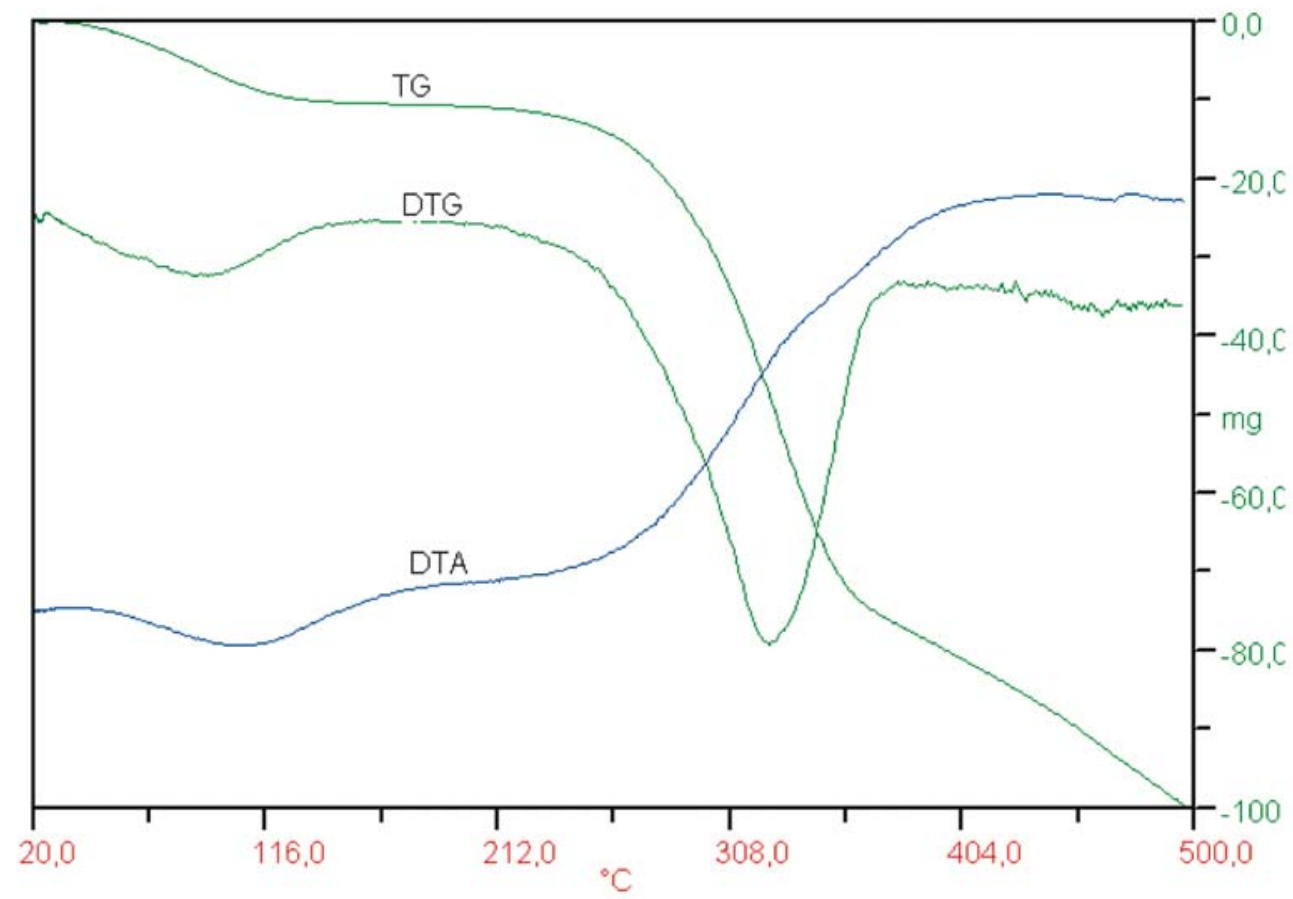

Figure 3. PWB derivatogram

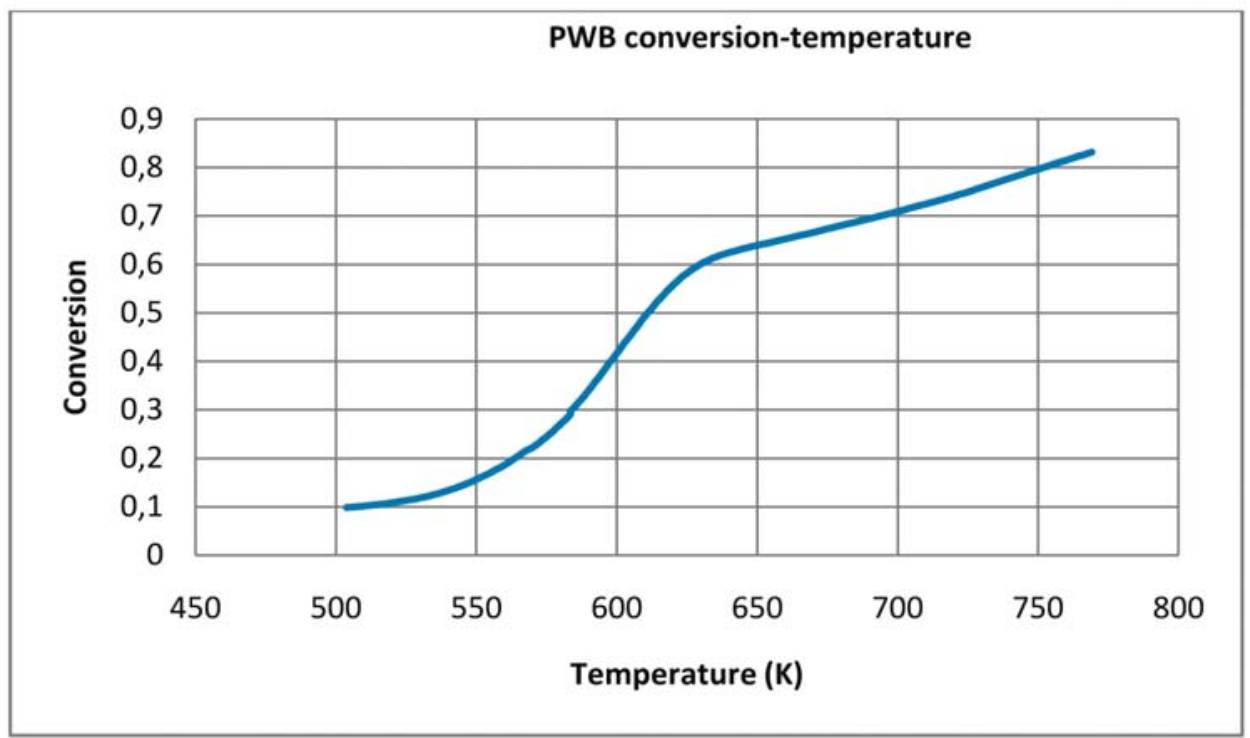

Figure 4. PWB conversion - temperature diagram 


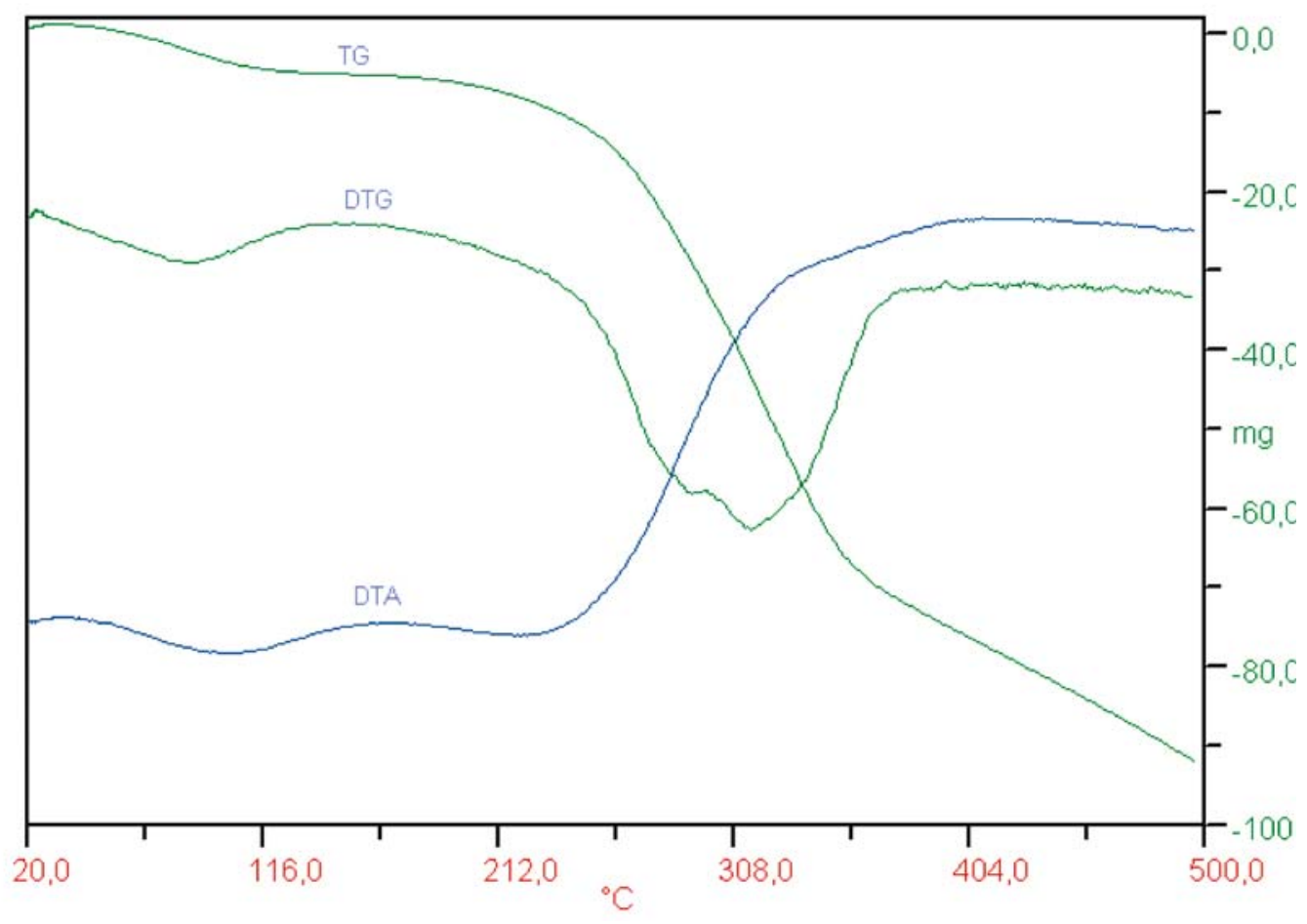

Figure 5. MPB derivatogram

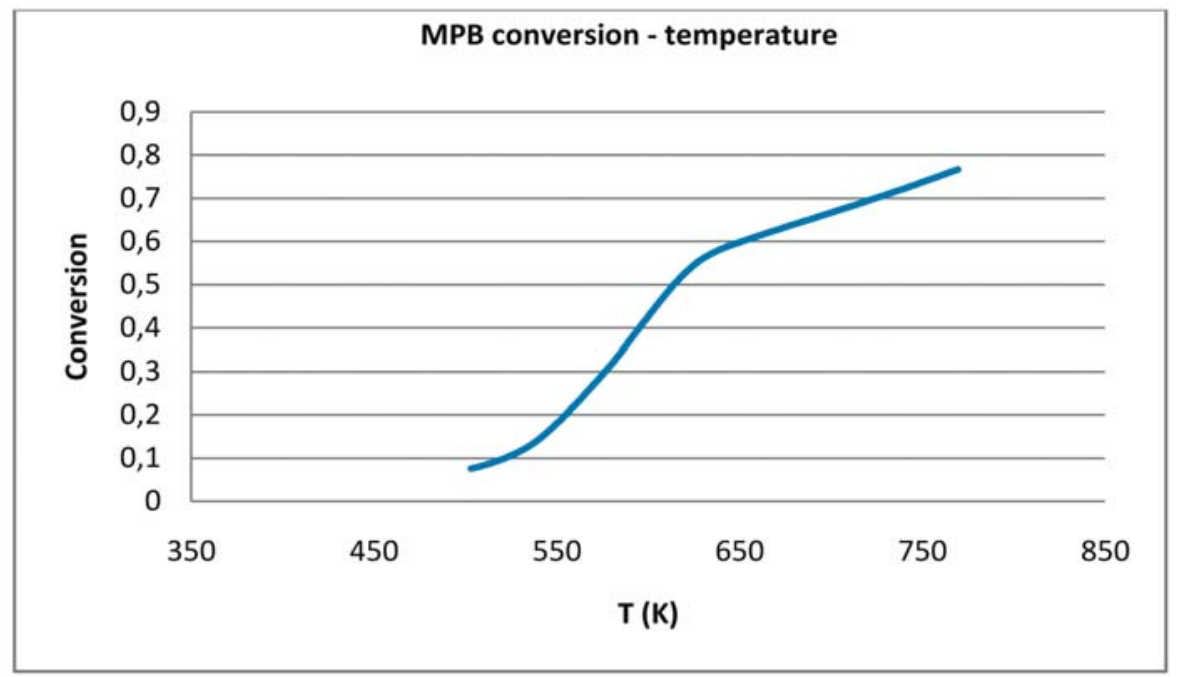

Figure 6. MPB conversion - temperature diagram 


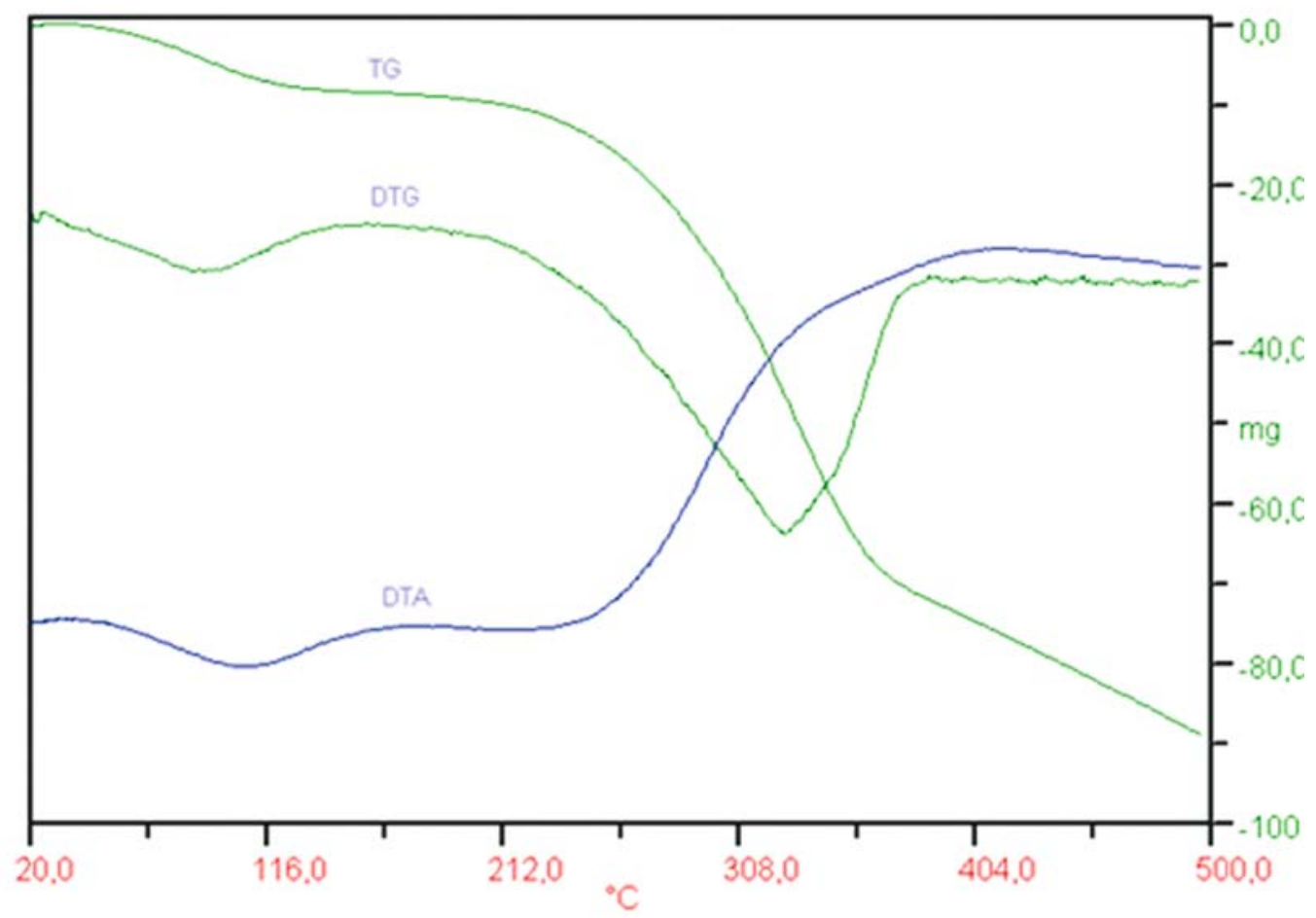

Figure 7. PBC derivatogram

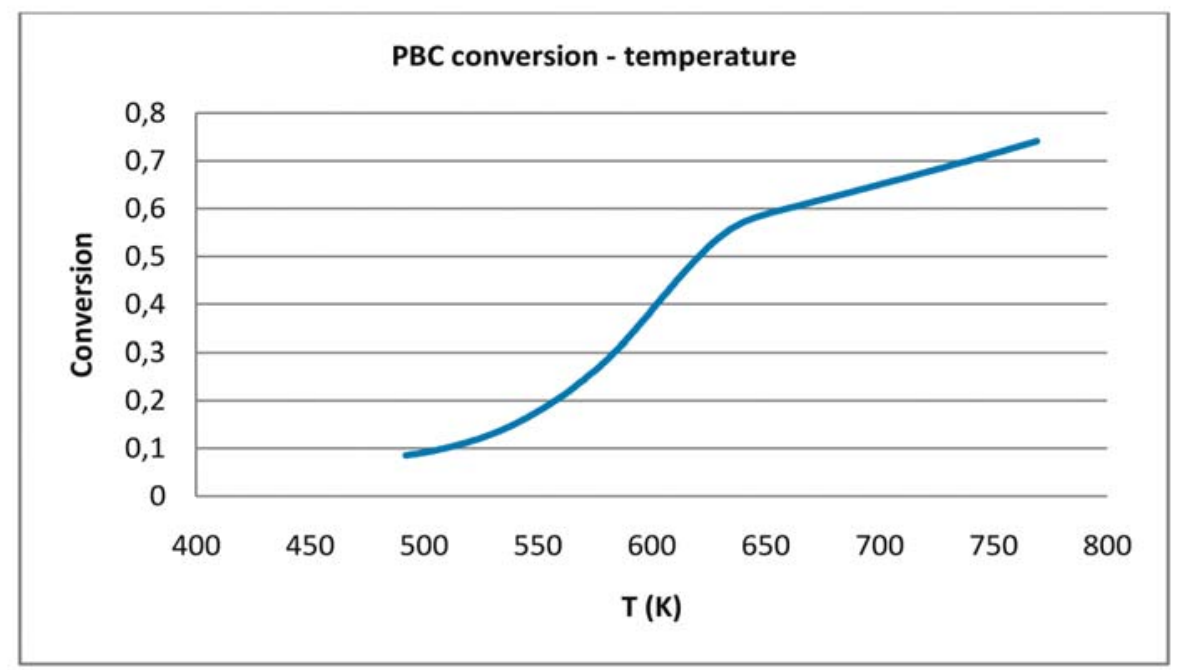

Figure 8. PBC conversion - temperature diagram 


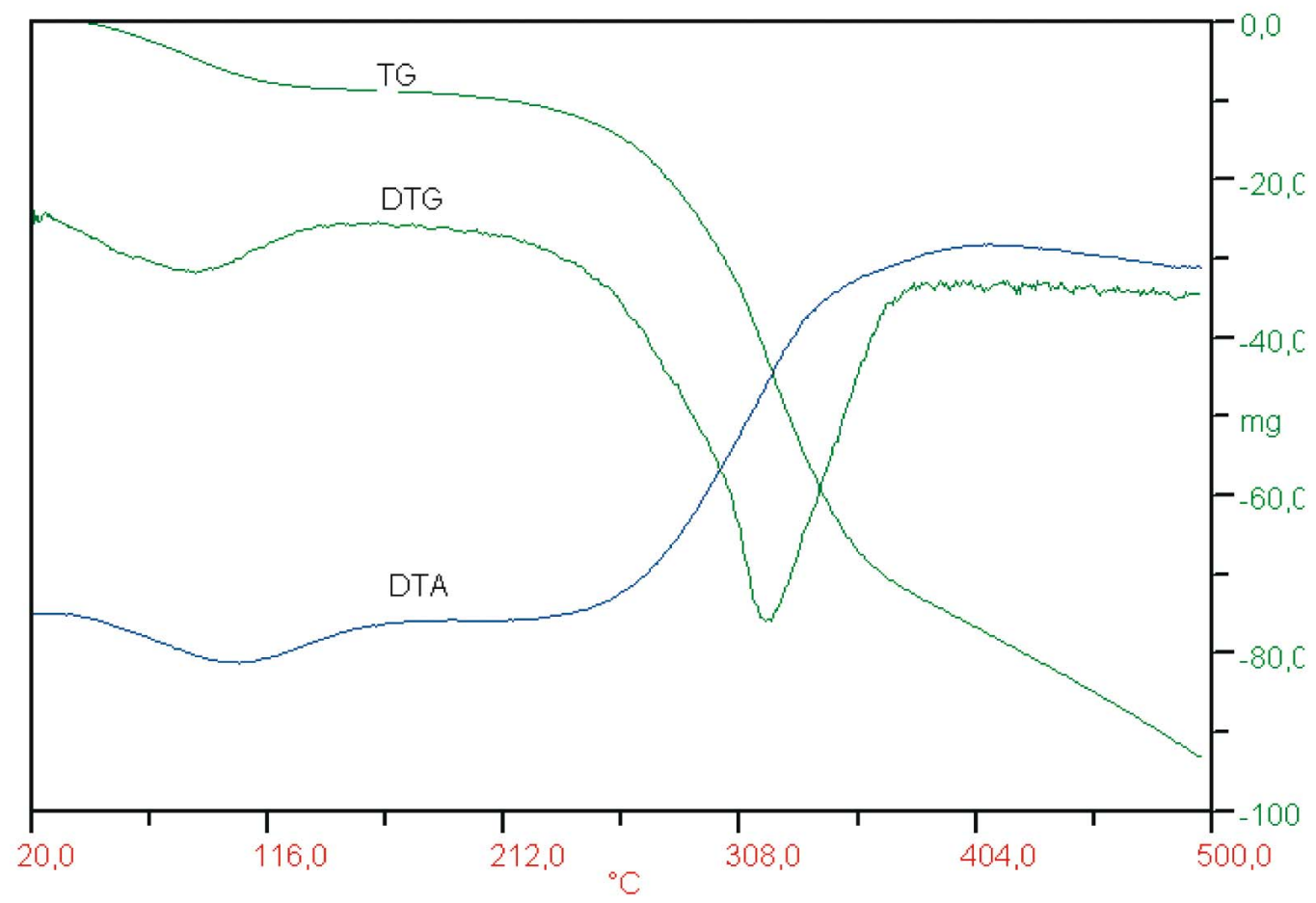

Figure 9. OSB derivatogram

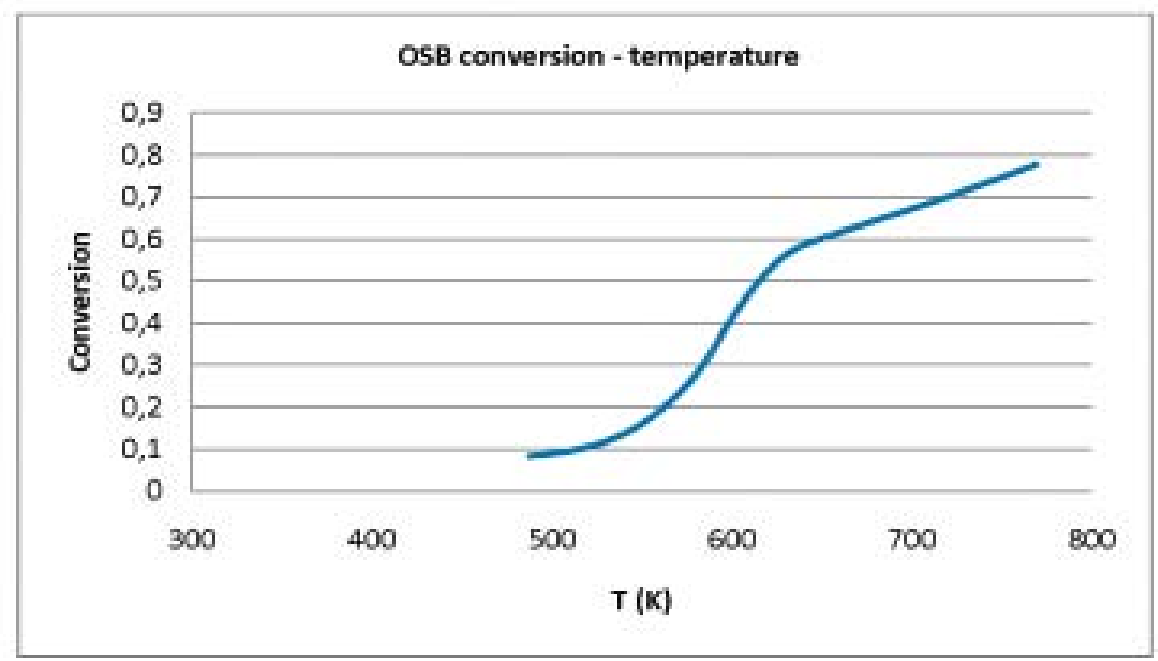

Figure10. OSB conversion - temperature diagram 


\subsection{Kinetics of thermal decomposition}

There are number of approaches to model the complex pyrolysis process. The simplest is the empirical model, which employs global kinetics, where the Arrhenius expression is used to correlate the mass loss rates with temperature.

The pyrolysis process of wood can be represented by the following general reaction:

$$
\text { Wood } \stackrel{k}{r} \text { volatile }+ \text { solid }
$$

For analysing the kinetics of TG/DTG/DTA data, the model assumes that the rate of weight loss of the total sample is dependent only on the rate constant, the remaining weight of the sample and its temperature. In the field of thermal analysis, the rate of thermal decomposition is described almost exclusively by rate equations of type

$$
\frac{d \alpha}{d t}=k(T) \cdot f(\alpha)
$$

Where $\alpha, t, T$ and $k$ stand for the reacted fraction, conversion, time, temperature and rate coefficient, respectively, $\mathrm{f}(\alpha)$ denotes an appropriate function of $\alpha$. [5]

Assuming a first-order reaction the applied equation:

$$
\frac{d \alpha}{d t}=A e^{-\frac{E}{R T}}(1-\alpha)
$$

Definition of conversion:

$$
\alpha=\frac{\Delta m_{t}}{\Delta m_{\infty}}
$$

Where $\Delta m_{t}$ is the loss of mass at the time $t, \Delta m_{\infty}$ is the total loss of mass.

Taking the logarithm of both size of Eq. 4 ,

$$
\ln \left(\frac{d \alpha}{d t}\right)=\ln A-\frac{E}{R} \cdot \frac{1}{T}+\ln (1-\alpha)
$$

Introducing the following notations:

$$
\begin{aligned}
& \ln \left(\frac{d \alpha}{d t}\right)=y, \quad \ln \mathrm{A}=p_{1}, \quad-\frac{E}{R}=p_{2}, \text { and } \quad \frac{1}{T}=x \text {, Eq.(6) can be written: } \\
& y=p_{1}+p_{2} x+\ln (1-\alpha)
\end{aligned}
$$

Rearranging Eq.(7):

$$
y-\ln (1-\alpha)=Y=p_{1}+p_{2} x
$$

A plot of $Y$ vs. $x$ (i.e. $1 / T$ ) will give a straight line with slope $p_{2}$ (i.e. $-E / R$ ) from which $E$ can be determined. The plot will also give an intersection with axis $\mathrm{Y}\left(p_{1}\right)$ from which $A$ can be determined. Results can be seen in Figures 11-14. 


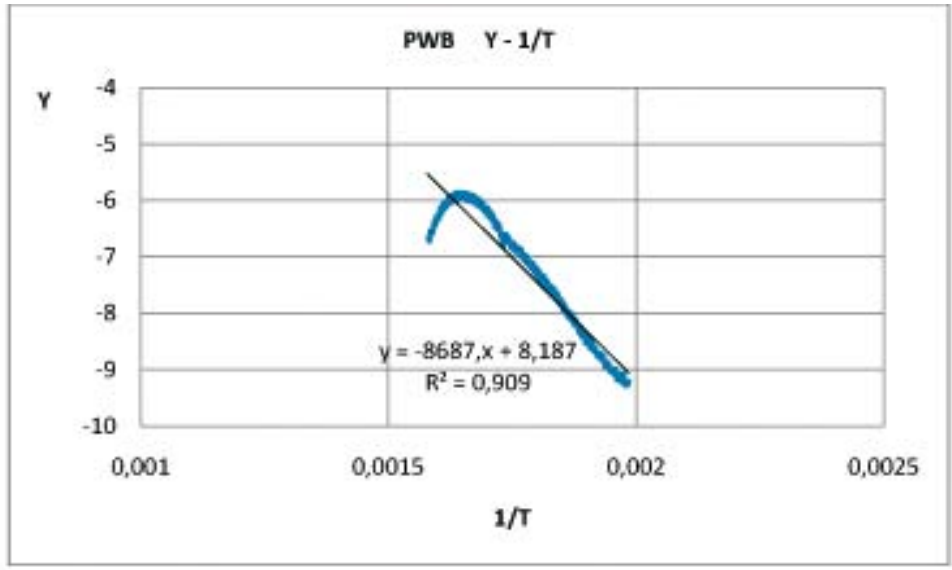

Figure11. PWB Y - 1/T diagram

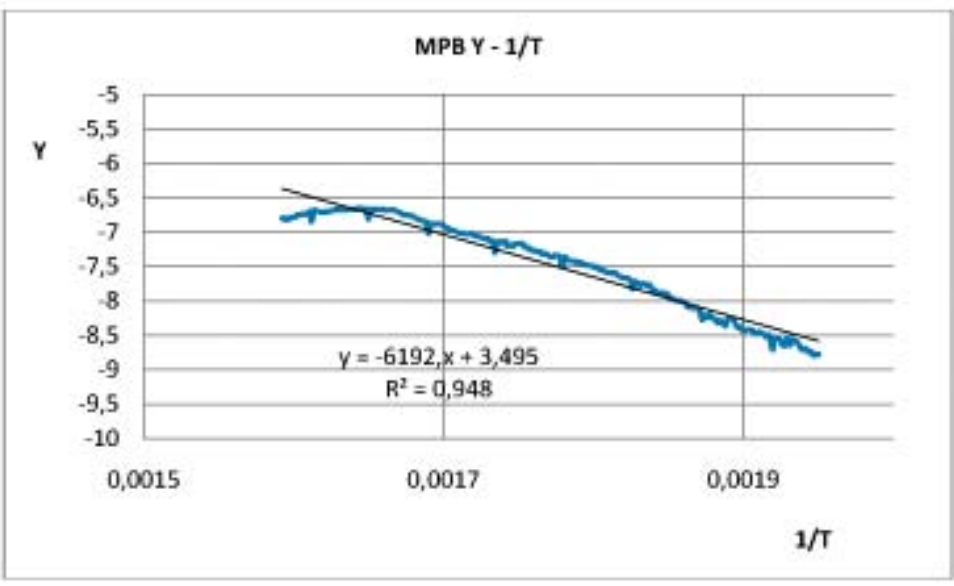

Figure 12. MPB Y - 1/T diagram

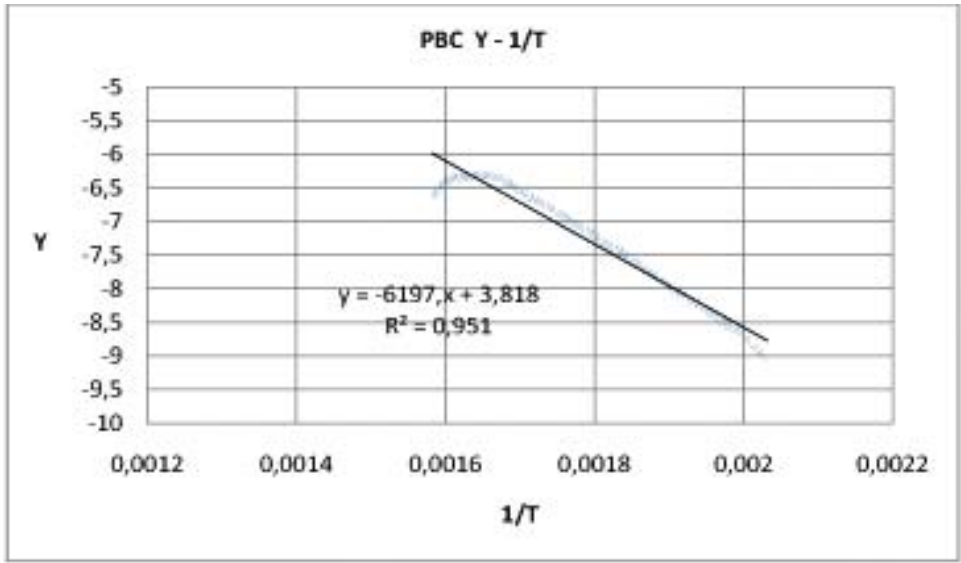

Figure 13. PBC Y - 1/Tdiagram 


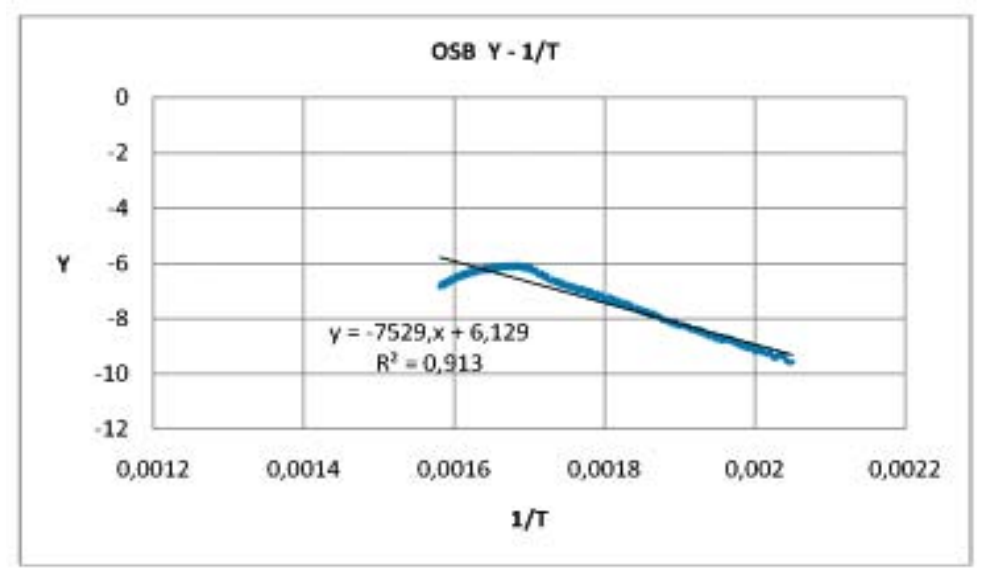

Figure 14. OSB Y - 1/T diagram

The activation energy (E) and pre-exponential factor (A) values were obtained from Fig. 11 - Fig. 14. The assumption of first-order reaction kinetics appears reasonable as can be seen in the figures.

The equations and the kinetic factors are summarized in Table 2.

\begin{tabular}{|c|c|c|c|c|}
\hline & Equation & $\mathrm{E}(\mathrm{kJ} / \mathrm{mol})$ & $\mathrm{A}(1 / \mathrm{min})$ & $\mathrm{R}^{2}$ \\
\hline PWB & $\mathrm{y}=-8687.6 \mathrm{x}+8.1873$ & 72.3 & $2.157 \times 10^{5}$ & 0.9094 \\
\hline MPB & $\mathrm{y}=-5763.5 \mathrm{x}+3.2499$ & 47.9 & $1.547 \times 10^{3}$ & 0.8741 \\
\hline PBC & $\mathrm{y}=-6197.1 \mathrm{x}+3.8186$ & 51.5 & $2.732 \times 10^{3}$ & 0.9516 \\
\hline OSB & $\mathrm{y}=-7529.1 \mathrm{x}+6.1296$ & 62.6 & $2.755 \times 10^{4}$ & 0.9131 \\
\hline
\end{tabular}

Table 2. Equations and kinetic factors of the pyrolysis

\section{CONSLUSIONS}

The aim of our work was to gain gross kinetic parameters for fire modelling for some wood products. The samples were heated in Derivatograph $Q 1500 D$ in static air atmosphere. For analysing the kinetics of TG/DTG/DTA data, the model assumes that the rate of weight loss of the total sample is dependent only on the rate constant, the remaining weight of the sample and its temperature. Pyrolisis takes place between 220 and $360^{\circ} \mathrm{C}$.

The activation energy (E) and pre-exponential factor (A) values were obtained from Fig. 11 - Fig. 14. The assumption of first-order reaction kinetics appears reasonable as can be seen in the figures. Our results are in good agreement with data can be find in literature $[6,7,8]$ 


\section{REFERENCES}

[1] Anca-Couce A. et al: Smouldering of pine wood: Kinetics and reaction heat, Combustion and Flame 159 (2012) pp.1708-1719

[2] Ed. Kevin Grattan: Fire Dynamics Simulator (V.4) Technical Reference Guide (2006), p. 30

[3] Paulik F., Paulik J., Erdey L., Z. Anal. Chem., 160 (1958) 241

[4] White R. H. and Dietenberger M. A.: Encyclopedia of Materials: Science and Technology, Elsevier Science Ltd. (2001)p p. 9712-9716

[5] Pokol Gy., VÁrhegy G.: Kinetic aspects of thermal analysis, CRC Critical Reviews in Analitical Chemistry, vol. 19, Issue 1(1988)pp.65-93

[6] Sebio-Punal, T. ET AL: Thermogravimetric analysis of wood, holocellulose, and lignin from five wood species, J Therm Anal Calorim (2012) 109, pp. 1163-1167

[7] Pétrissans, A.et al: Experimental and numerical analysis of wood thermodegradation. Mass loss kinetics, J Therm Anal Calorim (2012) 109, pp.907-914

[8] Poletto, M. et AL: Thermal decomposition of wood: Kinetics and degradation mechanisms, Bioresource Technology 126 (2012) pp.7-12 